\title{
Water Intake Before Bed Decreases the Morning Platelet Activity in At-Risk Patients
}

\author{
Paluch $\mathrm{Z}^{1,2 *}$, Pallag $\mathrm{G}^{1}$, Mlichová $\mathrm{J}^{1}$, Šimandl $\mathrm{O}^{1}$ and Alušík Šํ, \\ ${ }^{1}$ Institute of Pharmacology, Second Faculty of Medicine in Prague, Charles University, Prague, Czech Republic \\ ${ }^{2}$ St. John Nepomucene Neumann Institute, Příbram, Czech Republic and St. Elisabeth University of Health Care and Social Work, Bratislava, Slovak \\ Republic \\ ${ }^{3}$ Department of Internal Medicine, Postgraduate Medical School, Prague, Czech Republic
}

${ }^{*}$ Corresponding author: Zoltán Paluch, Department of Pharmacology and Pharmacy, General University Hospital, Na Bojišti 1, 12808 Praha 2, Czech Republic; E-mail: Paluch.Z@seznam.cz

Received: February 16, 2021; Accepted: February 22, 2021; Published: February 25, 2021

\begin{abstract}
Background: Platelet activity is a major risk factor for developing thrombosis and cardiovascular and cerebrovascular complications, with almost half of these occurring in the morning.

The aim of our study was to assess the effect of potable water intake on platelet activity in the morning.

Method: Using a VerifyNow system, we evaluated the laboratory parameters and morning platelet activity in a group of ( $\mathrm{n}=85$ ) outpatients on followup in a clinic of internal medicine. All enrolled patients were asked to drink $400 \mathrm{~mL}$ of water every evening before bed, with the laboratory investigations repeated the next morning.
\end{abstract}

Results: In a subgroup of patients with a higher baseline degree of platelet activity, intake of 0.4 liters of water before bed led to a statistically significant $(\mathrm{p}=0.0002)$ decrease in platelet activity.

Conclusion: Our data suggest that, in patients at increased risk of cardiovascular and cerebrovascular complications, water intake before bed will decrease platelet aggregation in the morning.

\section{Introduction}

Water is an essential component of the human body. Regular water intake has a beneficial impact on the functioning of individual blood cell types $[1,2]$. The impact of water intake on cell function has not been conclusively determined yet. Platelet activity plays a key role in the development of cardiovascular and cerebrovascular complications potentially progressing to thrombotic events $[3,4]$. The mortality rates of patients with increased thromboxane levels are 3.5 times higher compared with those with lower thromboxane levels, with an association between the rates of thrombotic events, platelet activity and thromboxane levels documented by a number of studies [5-7]. Platelet activity can be determined by a variety of techniques, one of them being use of the VerifyNow system (ITC, Edison, NJ, USA) $[7,8]$.

\section{Aim of the Study}

Our study was designed to show that determine whether or not intake of $400 \mathrm{~mL}$ of water before bed has an effect of platelet activity in the morning.

\section{Method}

The study was a project conducted from April to August 2018 in a Prague-based clinic of internal medicine. The study protocol was reviewed and approved by the Ethics Committee of the Second Faculty of Medicine in Prague, Charles University, Prague, Czech Republic.

\section{Patients}

Of the originally enrolled 100 volunteers, 15 were excluded from the study based on the results of their baseline assessment, making the final number of study participants 85 (51 men, 34 women. Those included had their platelet activity assessed in the morning after an overnight fast using a VerifyNow system and blood drawn for blood count, blood coagulation parameters and for blood biochemistry and first morning urine specimen assessment. The participants were asked to drink the evening before $400 \mathrm{~mL}$ of water before bed. The next morning, they presented for a follow-up examination with all the procedures repeated.

The study participants were outpatients ages 33 to 87 years (mean age of $61 \pm 14$ years) who were on follow-up in a Prague-based clinic of internal medicine. The exclusion criteria were antiplatelet or anticoagulation therapy, a malignancy, hematologic, liver or kidney disease, and/or current laboratory signs of dehydration. Also ineligible for the study were patients with a history of diarrhea and signs of dehydration or disorders of water intake or those with acute infection. Hydration status was determined by measuring specific urine gravity 
in the patients' first morning sample. Patient characteristics are shown in Tables 1-6.

\section{VerifyNow System}

Platelet activity was assessed using the VerifyNow system (ITC, Edison, NJ, USA). The results of the test indicate the amount of

Table 1: Anthropometric characteristics of the study group.

\begin{tabular}{|l|c|}
\hline Anthropometric characteristics of the study group $(\mathrm{n}=85)$ \\
\hline Age (years) & $62 \pm 13$ \\
\hline Women, $\mathrm{n}(\%)$ & $34(40)$ \\
\hline Body weight $(\mathrm{kg})$ & $84.7 \pm 19$ \\
\hline Height $(\mathrm{cm})$ & $174 \pm 9.4$ \\
\hline BMI (body mass index) $\left(\mathrm{kg} / \mathrm{m}^{2}\right)$ & $27.9 \pm 5.4$ \\
\hline BSA (body surface area) $\left(\mathrm{m}^{2}\right)$ & $1.99 \pm 0.24$ \\
\hline
\end{tabular}

Table 2: Hematologic parameters of the study group.

\begin{tabular}{|l|c|}
\hline Erythrocyte sedimentation rate $(\mathrm{mm} / \mathrm{h})$ & $27 \pm 20$ \\
\hline Leukocytes $\left(\times 10^{9} / \mathrm{L}\right)$ & $6.5 \pm 1.9$ \\
\hline Hemoglobin $(\mathrm{g} / \mathrm{L})$ & $141.2 \pm 18.2$ \\
\hline Hematocrit $(\mathrm{L} / \mathrm{L})$ & $0.43 \pm 0.05$ \\
\hline Thrombocytes $\left(\times 10^{9} / \mathrm{L}\right)$ & $234.8 \pm 73.5$ \\
\hline Mean platelet volume $(\mathrm{fL})$ & $11.07 \pm 0.95$ \\
\hline
\end{tabular}

Table 3: Biochemical characteristics of the study group.

\begin{tabular}{|l|c|}
\hline Creatinine $(\mu \mathrm{mol} / \mathrm{L})$ & $74.63 \pm 19.34$ \\
\hline Urea $(\mathrm{mmol} / \mathrm{L})$ & $5.5 \pm 1.97$ \\
\hline Calcium $(\mu \mathrm{mol} / \mathrm{L})$ & $2.37 \pm 0.09$ \\
\hline Phosphorus $(\mathrm{mmol} / \mathrm{L})$ & $0.96 \pm 0.18$ \\
\hline Zinc $(\mu \mathrm{mol} / \mathrm{L})$ & $18.65 \pm 3.21$ \\
\hline Magnesium $(\mathrm{mmol} / \mathrm{L})$ & $0.88 \pm 0.17$ \\
\hline Sodium $(\mathrm{mmol} / \mathrm{L})$ & $139.93 \pm 2.15$ \\
\hline Potassium $(\mathrm{mmol} / \mathrm{L})$ & $4.18 \pm 0.44$ \\
\hline Chlorine $(\mathrm{mmol} / \mathrm{L})$ & $104.46 \pm 2.94$ \\
\hline AST $($ aspartate transaminase $)(\mu \mathrm{kat} / \mathrm{L})$ & $0.44 \pm 0.18$ \\
\hline ALT $($ alanine transaminase $)(\mu \mathrm{kat} / \mathrm{L})$ & $0.53 \pm 0.38$ \\
\hline GGT $($ gamma-glutamyl transferase $)(\mu \mathrm{kat} / \mathrm{L})$ & $0.63 \pm 0.58$ \\
\hline Albumin $(\mathrm{g} / \mathrm{L})$ & $41.43 \pm 3.105$ \\
\hline Total protein $(\mathrm{g} / \mathrm{L})$ & $70.36 \pm 4.23$ \\
\hline Specific urine gravity $\left(\mathrm{kg} / \mathrm{m}^{3}\right)$ & $1017.2 \pm 7.1$ \\
\hline
\end{tabular}

Table 4: Values of biological markers as potential risk factors of atherosclerosis.

\begin{tabular}{|l|c|}
\hline CRP $(\mathrm{mg} / \mathrm{L})$ & $3.1 \pm 3.8$ \\
\hline Glucose $(\mathrm{mmol} / \mathrm{L})$ & $5.7 \pm 1.6$ \\
\hline Cholesterol $(\mathrm{mmol} / \mathrm{L})$ & $4.9 \pm 1.2$ \\
\hline TG $(\mathrm{mmol} / \mathrm{L})$ & $1.4 \pm 1.0$ \\
\hline HDL-cholesterol $(\mathrm{mmol} / \mathrm{L})$ & $1.3 \pm 0.3$ \\
\hline LDL-cholesterol $(\mathrm{mmol} / \mathrm{L})$ & $3.1 \pm 0.9$ \\
\hline
\end{tabular}

CRP - C-reactive protein; TG - triglycerides; HDL - high-density lipoprotein; LDL - lowdensity lipoprotein.

Table 5: Characteristics of the study group in terms of comorbidities.

\begin{tabular}{|l|c|}
\hline Comorbidities & Incidence, $\mathrm{n}=85(100 \%)$ \\
\hline Hypertension & $65(76.5 \%)$ \\
\hline Diabetes mellitus & $10(11.8 \%)$ \\
\hline Dyslipidemia & $46(54.1 \%)$ \\
\hline Vitamin D deficiency & $13(15.3 \%)$ \\
\hline History of peptic ulcer disease & $7(8.2 \%)$ \\
\hline
\end{tabular}

Table 6: Comparison of individual quartiles.

\begin{tabular}{|l|c|c|c|}
\hline Quartile number & Q1 & Q2+Q3 & Q4 \\
\hline Number of patients & 21 & 43 & 21 \\
\hline VerifyNow assay (units) & $417.8 \pm 42.4$ & $563.4 \pm 41.4$ & $642 \pm 14.0$ \\
\hline Mean platelet volume (fL) & $10.9 \pm 1.0$ & $11.1 \pm 11.2$ & 11.0 \\
\hline BMI $\left(\mathrm{kg} / \mathrm{m}^{2}\right)$ & $29.8 \pm 5.9$ & $27.5 \pm 5.5$ & $26.4 \pm 3.9$ \\
\hline Platelets $\left(\times 10^{9} / \mathrm{L}\right)$ & $224.7 \pm 75.1$ & $228.4 \pm 70.3$ & $260.7 \pm 64.4$ \\
\hline Fibrinogen & $2.9 \pm 0.7$ & $3.0 \pm 0.5$ & $3.0 \pm 0.7$ \\
\hline Urea $(\mathrm{mmol} / \mathrm{L})$ & $5.8 \pm 1.8$ & $5.5 \pm 1.7$ & $5.3 \pm 2.7$ \\
\hline Glucose $(\mathrm{mmol} / \mathrm{L})$ & $5.7 \pm 1.2$ & $5.7 \pm 1.5$ & $5.6 \pm 2.2$ \\
\hline Water intake (L)/body weight $(\mathrm{kg})$ & $0.007 \pm 0.002$ & $0.008 \pm 0.005$ & $0.01 \pm 0.006$ \\
\hline$\Delta \mathrm{TBX}($ units) & $-59.6 \pm 96.2$ & $-11.8 \pm 85.1$ & $46.7 \pm 63.5$ \\
\hline$\Delta \mathrm{TBX}(\%)$ & $-15.3 \pm 26.1$ & $-2.4 \pm 15.5$ & $7.3 \pm 10.0$ \\
\hline
\end{tabular}

$\triangle \mathrm{TBX}$ - difference in VerifyNow results before and after measurement.

thromboxane B2-(TBX) mediated activation of GP IIb/IIIa receptors involved in platelet aggregation. It is a turbidometric-based optical detection system utilizing a single-use cartridge with microbeads and fibrinogen-coated thrombocyte agonists to measure platelet-induced aggregation. The assay determines the capacity of activated platelets to bind to fibrinogen expressed as the ratio of platelets aggregated on fibrinogen-coated microbeads to the number of activated GPIIb/IIIa receptors. The intensity of the detected optical signal is proportionate to thromboxane (platelet) activity. The manufacturer's specification for the coefficient of variation is $\leq 10 \%$. Generally, it is a readily available assay with a closed system [9]. The assay, performed within 5 minutes of blood sampling, is employed in cardiac surgery to predict the risk of postoperative bleeding [7].

\section{Statistical Analysis}

The results are presented as means \pm standard deviation with quantitative data and as percentage with qualitative data. For statistical analysis of data, the two-sample T-test, Mann-Whitney non-parametric test, analysis of variance (ANOVA) and the $\chi^{2}$ test in frequency tables were used. With values that do not have Gaussian distribution, logarithmic transformation was used.

\section{Results}

Division of the enrolled volunteers by their baseline values assigned 21 patients to the first quartile (Q1) with VerifyNow assay units below 471, 43 patients to the intermediate quartiles (Q2+Q3) with 472-619 units, and 21 patients to the fourth quartile (Q4) with 620 units and over.

No statistically significant differences between the quartiles were noted in leukocyte count, erythrocyte sedimentation rate, mean platelet volume (MPV), fibrinogen levels, urea, glycemia, and water intake.

Compared with the Q4 group, patients in Q1 had a significantly higher BMI ( $\mathrm{p}=0.03)$.

Compared with the Q4 group, Q1 patients had a significantly lower platelet count $(\mathrm{p}=0.03)$ and their water intake to $\mathrm{kg}$ body weight was significantly lower $(\mathrm{p}=0.047)$. Platelet activity in the morning after drinking $400 \mathrm{~mL}$ of water the night before was significantly lower in Q4 patients compared with the Q1 group. The difference between 
platelet activity values $(\triangle \mathrm{TBX})$ was significantly greater in $\mathrm{Q} 4$ patients compared with the $\mathrm{Q} 1$ group both in absolute figures $(\mathrm{p}=0.0002)$ and percentage ( $\mathrm{p}=0.001)$. This finding suggests that, in patients with high baseline platelet activity, drinking of $400 \mathrm{~mL}$ of water before bed does affect platelet activity.

\section{Discussion}

As the main component of the human body, water plays a critical role in almost all life processes. Potable water is absorbed from the gastrointestinal tract within 5 minutes of intake and becomes detectable in blood cells. Assuming an average consumption of 2 liters of water per day and the biological half-life of water in a healthy individual of 10 days, $99 \%$ of water in the body gets completely exchanged within some 50 days [10]. The scientific literature addressing the effects of alcoholic drinks, of tea and coffee as the most popular beverages, and of sugar-sweetened beverages on individual organ systems drinks is more abundant compared with that examining the effect of water intake [11-18].

Potable water is generally considered the best liquid for body hydration and maintenance of water homeostasis in a healthy population [19-21]. Regular consumption of sufficient amounts of drinking water has been conclusively shown to play a major role in the prevention of malignancies [urinary bladder cancer, colorectal cancer), urinary tract infection, nephrolithiasis, obesity, constipation, migraine, bronchial asthma, skin disorders and depression [22-27]. Earlier studies showed that intake of $300 \mathrm{ml}$ of potable water after a 12-hour fast had a significant impact on the biochemical parameters of blood, i.e., total protein, urea, bilirubin, total cholesterol, triglycerides, uric acid, aspartate transaminase (AST), gamma-glutamyl transferase (GGT) and lactate dehydrogenase [28].

A prospective study enrolling 20,000 patient with coronary heart disease investigated the importance of regular daily consumption of more than 1 liters of water. The male arm of the study showed an almost $54 \%$ reduction in cardiovascular mortality without a significant effect in the female arm with only a $13 \%$ decrease in cardiovascular mortality [29]. Water intake has multiple effects on the body and affects the proper functioning of cellular elements, coagulation factors, hydration, viscosity and other hemodynamic parameters as well as the incidence of cardiovascular complications $[1,2,30]$.

Regular water intake exerts a beneficial effect of hormonal activity while reducing the levels of hs-CRP as a marker of inflammation and a risk factor for cardiovascular disease [1,31]. Likewise, regular consumption of 2 liters of water has an effect on the erythrocytes, the cell components of blood, significantly raising mean hemoglobin concentrations $(\mathrm{MCH})$, mean corpuscular hemoglobin concentration (MCHC) while significantly decreasing mean platelet volume and, indirectly, also blood coagulation and hemodynamic parameters [1]. Adequate hydration is crucial for hemoglobin synthesis, transformation of deoxygenated hemoglobin to its oxidized form and its allosteric conformation $[2,30]$.

Thrombocytes play a key role in platelet aggregation and pathophysiology of thrombotic complications. Platelet size (mean platelet volume, MPV) is an independent risk factor for cardiovascular disease [28,32-35]. Patients with a higher MPV who had had a myocardial infarction or myocardial revascularization have a poorer prognosis or are at increased risk of stent restenosis. The mechanism and causal relationship between MPV and increased incidence of thrombotic complications experienced by coronary heart disease patients have not been clearly established to date [32]. Likewise, we have been unable to demonstrate a correlation with MPV and platelet activity. Results of meta-analyses document a higher incidence of cardiovascular events in the period around morning awakening. The risk is $40 \%$ higher for myocardial infarction, $29 \%$ for sudden cardiac death, and $49 \%$ for stroke [36]. The morning incidence of cardiovascular and cerebrovascular events is affected by several factors including sympathetic system activity, increased blood pressure and heart rate, cardiac output, peripheral resistance and platelet aggregation [37].

A correlation between high thromboxane levels and incidence of cardiovascular and cerebrovascular events has been reported by several studies [5-7]. Our data have demonstrated the impact of consumption of $400 \mathrm{~mL}$ of water before bed on the morning platelet activity in a subgroup of patients with enhanced platelet activity and, hence, increased thromboxane levels. The implication is that intake of $400 \mathrm{~mL}$ of water before bed in at-risk patients will significantly reduce platelet activity as a major risk factor for thrombotic complications. Similar results were reported by Maehashi suggesting that water intake before bed will attenuate morning platelet activity [38].

\section{Study Limitations}

A major limitation of our study is the relatively small number of participants. Further studies are definitely warranted to obtain conclusive evidence of the clinical importance of regular water intake on the incidence of cardiovascular and cerebrovascular events and/or patient prognosis.

\section{Conclusion}

Intake of water and its impact on the individual functions of the components of blood and organ system, hemostasis and blood coagulation parameters is a most intricate and intertwined process. Physiological functions associated with water metabolism are capable of making up for single changes in relatively small amounts of fluids without critically affecting their function. Regarding the incidence of cardiovascular and cerebrovascular events in at-risk patients, intake of $400 \mathrm{~mL}$ of water before bed significantly reduces platelet activity. Our data suggest that regular consumption of water by at-risk patients may help reduce the risk of cardiovascular and cerebrovascular events in the morning hours. However, this hypothesis needs to be supported and/or confirmed by further studies.

\section{References}

1. HK Kim, SH Kim, JK Ryu (2017) Changes in the Blood Components Caused by Water Intake. Korean J Clin Lab Sci 49: 227-232.

2. Colombo MF, Rau DC, Parsegian VA (1992) Protein solvation in allosteric regulation: a water effect on hemoglobin. Science 256: 655-659. [crossref]

3. Roth GA, Huffman MD, Moran AE, Feigin V, Mensah GA, et al. (2015) Global and regional patterns in cardiovascular mortality from 1990 to 2013. Circulation 132:1667- 1678. [crossref] 
4. Oksak GA, Golovanova IA (2017) Contribution of mortality from cardiovascular disease to overall mortality. Wiad Lek 70: 449-455. [crossref]

5. Eikelboom JW, Hirsh J, Weitz JI, Johnston M, Yi Q, et al. (2002) Aspirin-resistant thromboxane biosynthesis and the risk of myocardial infarction, stroke, or cardiovascular death in patients at high risk for cardiovascular events. Circulation 105: 1650-1655. [crossref]

6. Patrono C, Ciabattoni G, Pugliese F, Pierucci A, Blair IA, et al. (1986) Estimated rate of thromboxane secretion into the circulation of normal humans. J Clin Invest 83: 590-594. [crossref]

7. Renda G, De Caterina R (2012) Measurements of thromboxane production and their clinical significance in coronary heart disease. Thromb Haemost 108: 6-8. [crossref]

8. Paniccia R, Priora R, Liotta AA, Abbate R (2015) Platelet function tests: a comparative review. Vasc Health Risk Manag 11: 133-148. [crossref]

9. Smith JW, Steinhubl SR, Lincoff AM, J C Coleman, T T Lee, et al. (1999) Rapid platelet-function assay: an automated and quantitative cartridge-based method. Circulation 99: 620-625. [crossref]

10. Peronnet F, Mignault D, du SP, Vergne S, Le BL, et al. (2012) Pharmacokinetic analysis of absorption, distribution and disappearance of ingested water labeled with D(2)O in humans. Eur J Appl Physiol 112: 2213-2222. [crossref]

11. Imamura F, O'Connor L, Ye Z, Mursu J, Hayashino Y, et al. (2016) Consumption of sugar sweetened beverages, artificially sweetened beverages, and fruit juice and incidence of type 2 diabetes: systematic review, meta-analysis, and estimation of population attributable fraction. Br J Sports Med 50: 496-504. [crossref]

12. Jayalath VH, de Souza RJ, Ha V, Mirrahimi A, Blanco-Mejia S, et al. (2015) Sugarsweetened beverage consumption and incident hypertension: a systematic review and meta-analysis of prospective cohorts. Am J Clin Nutr 102: 914-921. [crossref]

13. Tang J, Zheng JS, Fang L, Jin Y, Cai W, et al. (2015) Tea consumption and mortality of all cancers, CVD and all causes: a meta-analysis of eighteen prospective cohort studies. Br J Nutr 114: 673-683. [crossref]

14. Crippa A, Discacciati A, Larsson SC, Wolk A, Orsini N (2014) Coffee consumption and mortality from all causes, cardiovascular disease, and cancer: a dose-response meta-analysis. Am J Epidemiol 180: 763-775. [crossref]

15. Zhang X, Albanes D, Beeson WL, van den Brandt PA, Buring JE, et al. (2010) Risk of colon cancer and coffee, tea, and sugar-sweetened soft drink intake: pooled analysis of prospective cohort studies. J Natl Cancer Inst 102: 771-783. [crossref]

16. Huxley R, Lee CM, Barzi F, Timmermeister L, Czernichow S, et al. (2009) Coffee, decaffeinated coffee, and tea consumption in relation to incident type 2 diabetes mellitus: a systematic review with meta-analysis. Arch Intern Med 169: 2053-2063. [crossref]

17. Wu JN, Ho SC, Zhou C, Ling WH, Chen WQ, et al. (2009) Coffee consumption and risk of coronary heart diseases: a meta-analysis of 21 prospective cohort studies. Int $J$ Cardiol 137: 216-225. [crossref]

18. Ashima KK, Graubard B (2017) A prospective study of water intake and subsequent risk of all-cause mortality in a national cohort. Am J Clin Nutr 105: 212-220. [crossref]

19. Food and Nutrition Board (2004) Panel on Dietary Reference Intakes for Electrolytes and Water. Dietary Reference Intakes for water, potassium, sodium, chloride, and sulfate. Washington (DC): National Academy Press.

20. EFSA Panel on Dietetic Products, Nutrition, and Allergies (NDA) (2010) Scientific opinion on Dietary Reference Values for water. EFSA J 8: 1459.
21. Valtin H (2002) "Drink at least eight glasses of water a day." Really? Is there scientific evidence for "8 x 8"? Am J Physiol Regul Integr Comp Physiol 283: R993-1004. [crossref]

22. Lappalainen R, Mennen L, van Weert L, and Mykkanen H (1993) Drinking water with a meal: a simple method of coping with feelings of hunger, satiety and desire to eat. Eur J Clin Nutr 47: 815-819. [crossref]

23. Rolls BJ, Bell EA, and Thorwart ML (1999) Water incorporated into a food but not served with a food decreases energy intake in lean women. Am J Clin Nutr 70: 448455. [crossref]

24. Rolls BJ, Castellanos VH, Halford JC, Kilara A, Panyam D, et al. (1998) Volume of food consumed affects satiety in men. Am J Clin Nutr 67: 1170-1177. [crossref]

25. Stookey JD (2001) Energy density, energy intake and weight status in a large freeliving sample of Chinese adults: exploring the underlying roles of fat, protein, carbohydrate, fiber and water intakes. Eur J Clin Nutr 55: 349-359. [crossref]

26. Anti M, Pignataro G, Armuzzi A, Valenti A, Iascone E, et al. (1998) Water supplementation enhances the effect of high-fiber diet on stool frequency and laxative consumption in adult patients with functional constipation. Hepatogastroenterology 45: 727-732. [crossref]

27. McCord H (2001) Are you drinking too much water? Prevention 53: 62-63.

28. Benozzi SF, Unger G, Campion A, Pennacchiotti LG (2018) Fasting conditions: Influence of water intake on clinical chemistry analytes. Biochem Med (Zagreb) 28: 010702. [crossref]

29. Chan J, Knutsen SF, Blix GG, Lee JW, and Fraser GE (2002) Water, other fluids, and fatal coronary heart disease. The Adventist Health Study. Am J Epidemiol 155: 827833. [crossref]

30. Bulone D, San Biagio PL, Palma-Vittorelli MB, Palma MU (1993) The role of water in hemoglobin function and stability. Science 259: 1335-1336. [crossref]

31. Soriano-Guillén L, Hernández-García B, Pita J, Domínguez-Garrido N, Del RíoCamacho G, et al. (2008) High-sensitivity C-reactive protein is a good marker of cardiovascular risk in obese children and adolescents. Eur J Endocrinol 159: R1-4. [crossref]

32. Chu SG, Becker RC, Berger PB, Bhatt DL, Eikelboom JW, et al. (2010) Mean platelet volume as a predictor of cardiovascular risk: a systematic review and meta-analysis. $J$ Thromb Haemost 8: 148-56. [crossref]

33. Burr ML, Holliday RM, Fehily AM, Whitehead P (1992) Haematological prognostic indices after myocardial infarction: evidence from the diet and reinfarction trial (DART) Eur Heart J 13:166-170. [crossref]

34. Martin JF, Bath PM, Burr ML (1991) Influence of platelet size on outcome after myocardial infarction. Lancet 338: 1409-1411. [crossref]

35. Cattela F, Healy D, Lawson JA, Fitzgerald GA (1986) 11-Dehydrothromboxane B2 a quantitative index of thromboxane $\mathrm{A} 2$ formation in the human circulation. PNAS 83: 5861-5865

36. Elliot WJ (2001) Cyclic and circadian variations in cardiovascular events. Am Hypertens 14: 291S-295S. [crossref]

37. Weber AM, Fodera MS (2004) Circadian Variations in Cardiovascular Disease Chronotherapeutic Approaches to the Management of Hypertension. Rev Cardiovasc Med 5: 148-155. [crossref]

38. Maehashi N, Sano H, Iwata S, Rin K, Ito Y (1996) Effect of a Water Intake on the Morning Surge of Platelet Activity. 276A ABSTRACTS-Poster JACC February 1996.

Citation:

Paluch Z, Pallag G, Mlichová J, Šimandl O, Alušík Š (2021) Water Intake Before Bed Decreases the Morning Platelet Activity in At-Risk Patients. J Cardiol Clin Pract Volume 4(1): 1-4. 